\title{
Dynamic Analysis and Control of an Automatic Transmission for Start-Stop Function and Efficiency Improvement
}

\author{
Yang Liu, ${ }^{1}$ Shuhan Wang, ${ }^{1}$ Peng Dong, ${ }^{2}$ and Xiangyang Xu ${ }^{1}$ \\ ${ }^{1}$ School of Transportation Science and Engineering, Beihang University, Beijing 100191, China \\ ${ }^{2}$ Chair of Industrial and Automotive Drivetrains, Department of Mechanical Engineering, Ruhr-University Bochum, \\ 44799 Bochum, Germany
}

Correspondence should be addressed to Shuhan Wang; wsh@buaa.edu.cn

Received 30 October 2014; Accepted 19 November 2014

Academic Editor: Hui Zhang

Copyright (C) 2015 Yang Liu et al. This is an open access article distributed under the Creative Commons Attribution License, which permits unrestricted use, distribution, and reproduction in any medium, provided the original work is properly cited.

\begin{abstract}
An electric oil pump (EOP) was integrated into the hydraulic system and an automatic transmission (AT) mechanical oil pump (MOP) was downsized. These processes were performed to combine a start-stop function with the AT and further improve the transmission efficiency. Furthermore, this study established a dynamics model of power loss and leakage of an 8-speed AT; a flowbased control algorithm of the EOP was then developed to realize the start-stop function and support the MOP to meet the flow requirement of the system. Based on a driving simulation method, sizes of the MOP and EOP that ensured optimal fuel economy were selected. A control strategy for the starting clutch was also developed to minimize the starting delay of the test vehicle. A test environment on a rig and prototype vehicle was established to verify the feasibility of the proposed control strategies. The test results indicated that the transmission functioned favorably with the novel two-pump system presented, and a quick and smooth starting performance was achieved when the engine was restarted. The findings in this study are extremely valuable for forward designs of an AT for realizing start-stop function and improving efficiency.
\end{abstract}

\section{Introduction}

Global environmental protection requirements, which have increased worldwide in recent years, have accelerated efforts for improving the fuel economy of vehicles. A typical example involves adopting engine start-stop function to reduce energy consumption when the vehicle is stopped, thus improving the urban environment [1]. This function shuts off the engine when the engine power is not required and restarts the engine when necessary. In the New European Driving Cycle (NEDC), this function can achieve a fuel economy improvement of approximately 5\% [2]. However, this function does not match well with automatic transmission (AT) because of the starting responsiveness and comfort. For a conventional AT, the oil pump mostly comprises a single mechanical oil pump (MOP) that is driven by the engine, and this pump does not operate when the engine stops. However, time is required for establishing the hydraulic pressure when the engine starts, thus delaying the vehicle driving off. To achieve a start-stop function for an AT-based vehicle, the hydraulic pressure must be maintained when the engine stops so that the forward gear clutch can quickly deliver the driving torque when the engine restarts. Establishing a control strategy for the starting clutch is also extremely crucial for the starting performance of a vehicle. Most conventional AT uses only a single MOP that is designed according to the lowest engine speed; therefore, the displacement of the MOP in general is extremely big, thus leading to a high loss of power when the engine runs at high speed. The hydraulic pressure can be maintained in AT by using an electric oil pump (EOP). In addition, the EOP can supplement the oil flow at low engine speeds; thus reducing the displacement of the MOP can improve the transmission efficiency further.

In recent years, numerous ATs use an EOP or HIS (hydraulic impulse storage) to achieve start-stop function [35]. A previous study analyzed the effect of pump selection on fuel economy [6] and a two-pump system (one EOP and one MOP) was suggested to replace the conventional AT MOP 


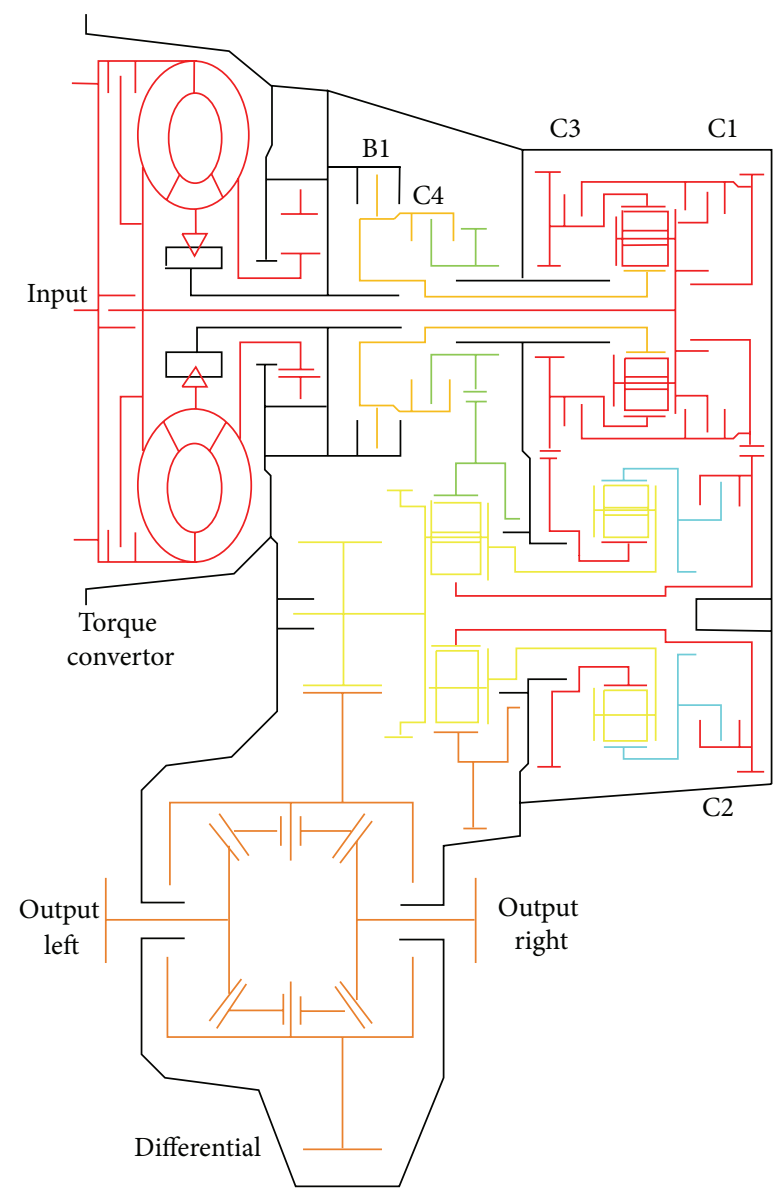

(a)

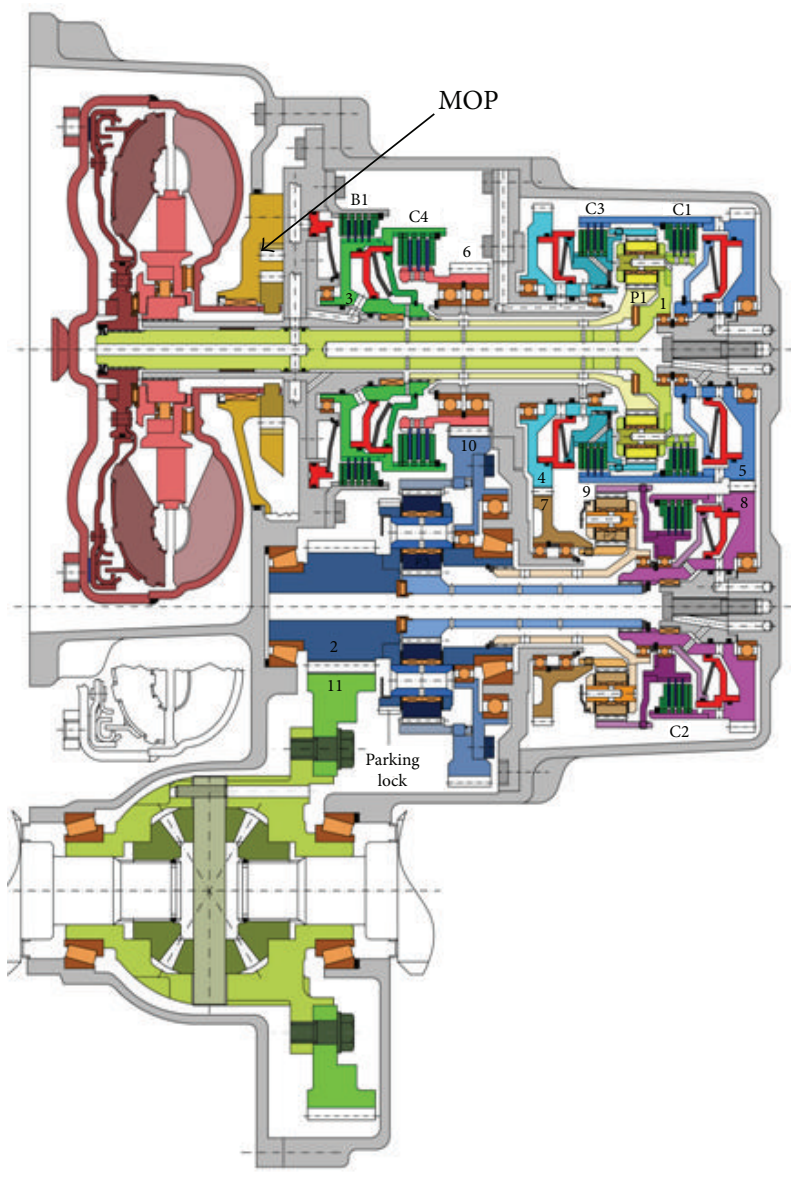

(b)

FIGURE 1: Structure of an 8AT.

[7]. However, these studies did not consider an approach for determining the size of the EOP and MOP to derive optimal efficiency. An EOP control algorithm was proposed to reduce energy consumption [8]. In [9], a control method that can keep the powertrain closed when an engine is being restarted to minimize the starting delay was proposed; however, in this control method, the starting delay was minimized at the expense of the starting smoothness. Nonetheless, a starter with a high driving torque occupies larger space and cost.

Figure 1 shows a two-dimensional structure of an 8 -speed AT (8AT) with five shift elements: a brake B1 and four clutches $\mathrm{C} 1-\mathrm{C} 4$. These shift elements can achieve eight forward gears and one reverse gear. A high displacement MOP $(17 \mathrm{~mL})$ is connected directly to the pump wheel of the torque converter. The objectives of this project were as follows.

(1) Replace the MOP with a two-pump system to achieve a start-stop function and further improve transmission efficiency.

(2) Develop an EOP control algorithm.

(3) Develop a strategy for controlling the starting clutch to achieve a quick and smooth vehicle starting performance.

\section{Dynamics Simulation Model}

The 8AT illustrated in Figure 1 is installed in an SUV called JMH X5 that was put into mass production in China. A dynamics model of this vehicle system was established in this study. The established model comprises a vehicle body, engine, 8AT, driver cockpit, differential, brake, tire, and other vehicle elements. The clutch shift control and torque converter lock-up control were also integrated into this model. A driving simulation can be achieved by running this model in typical driving cycles. The power loss and leakage model of this 8AT was established on the platform of the vehicle system by using the MathCAD software. This model supports controlling the EOP and using two pumps.

2.1. Power Loss Model. An AT has three types of power loss, and these are mechanical loss (shifting, bearing, and gear meshing), hydraulic loss (torque converter and oil pump), and electric loss (TCU, sensor, and solenoid). These losses generate heat in transmission. The mechanical loss is the main loss that must be cooled by the ATF (automatic transmission fluid).

2.1.1. Shifting Loss. Table 1 shows the shift logic of the 8AT. The entire shifting of this $8 \mathrm{AT}$ is clutch-to-clutch shifting. A 
TABLE 1: Shift logic.

\begin{tabular}{lccccc}
\hline \multirow{2}{*}{ Gear } & \multicolumn{5}{c}{ Engaged shifting element } \\
& $\mathrm{B} 1$ & $\mathrm{C} 1$ & $\mathrm{C} 2$ & $\mathrm{C} 3$ & $\mathrm{C} 4$ \\
\hline $\mathrm{R}$ & $\times$ & & $\times$ & & $\times$ \\
1 & $\times$ & $\times$ & & & $\times$ \\
2 & $\times$ & & & $\times$ & $\times$ \\
3 & & $\times$ & & $\times$ & $\times$ \\
4 & & & $\times$ & $\times$ & $\times$ \\
5 & & $\times$ & $\times$ & & $\times$ \\
6 & & $\times$ & $\times$ & $\times$ & \\
7 & $\times$ & $\times$ & $\times$ & & \\
8 & $\times$ & & $\times$ & $\times$ & \\
\hline
\end{tabular}

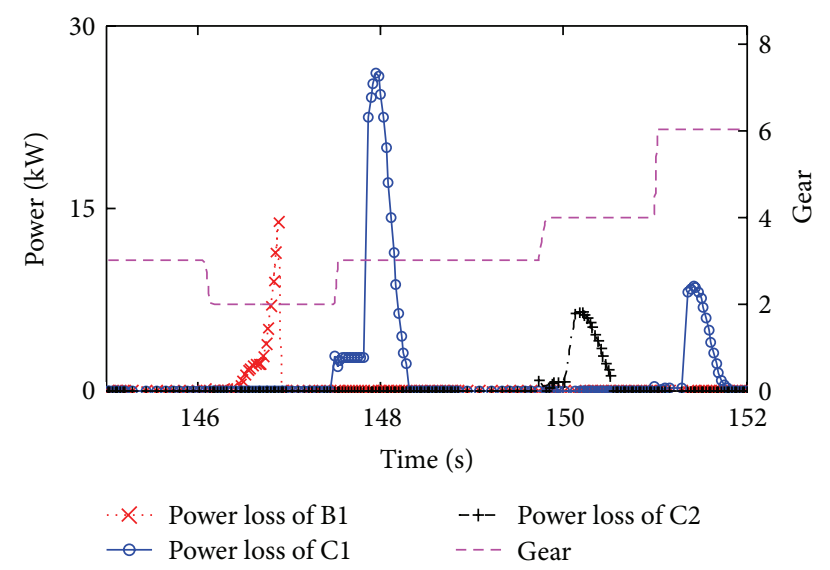

FIGURE 2: Simulation results of shifting power loss.

gear shift can be accomplished by disengaging an offgoing clutch and engaging an oncoming clutch. A torque estimation and slip control method is used to control the pressure of the clutch; the control method is detailed in [10].

The friction torque of the actuated shifting element during shifting can be calculated as follows:

$$
T_{S}=\mu_{d} \cdot\left(p_{\mathrm{SE}}-p_{\mathrm{KP}}\right) \cdot A \cdot r \cdot N \cdot \operatorname{sgn}(\Delta \omega),
$$

where $\mu_{d}$ represents the dynamic friction coefficient, $p_{\mathrm{SE}}$ denotes the pressure of the shifting element, $p_{\mathrm{KP}}$ is the pressure of clutch kiss-point, $A$ represents the friction area, $r$ denotes the friction radius, $N$ represents the number of friction facings, and $\Delta \omega$ is the angular speed difference. The shifting loss can be calculated as follows:

$$
P_{\text {loss_shift }}=\int T_{S}(t) \cdot \Delta \omega(t) \cdot d t .
$$

The power loss of shifting can be simulated by running this model in typical driving cycles. Figure 2 shows the shifting power loss of three shifting elements in a section of the SFTP US06 cycle, indicating that the shifting loss appears during each gear shift, and a gear shift can generate approximately $10-30 \mathrm{~kW}$ power loss in nearly 1 second; the loss is caused by the friction between the steel plates and friction plates of the clutch or brake, and its quantity depends on the friction torque and slip time during shift; the shifting power loss in low gears is bigger than in high gears, because the shifting elements must bear more friction torque in low gears to transmit more driving torque to the wheels by the 8AT. In addition, the power loss of $\mathrm{B} 1$ occurs during the gear shift of 32 , the power loss of $\mathrm{Cl}$ occurs during the gear shifts of 2-3 and $4-6$, and the power loss of $\mathrm{C} 2$ occurs during the gear shifts of 3-2; according to the shift logic, they are the oncoming clutches during these shifts. The power loss of shifting for the other gear shifts was caused by the corresponding activated shifting elements.

2.1.2. Bearing Loss. The 8AT used in this study has three types of bearings, and these are ball bearings, tapered roller bearings, and needle roller bearings. The friction torque of a bearing comprises two parts [11]: The first part is a function of speed-as shown in (3) - and the second part is a function of load-as shown in (4). Consider

$$
T_{1}= \begin{cases}f_{1} \cdot(v \cdot n)^{2 / 3} \cdot d_{M}^{3} \cdot 10^{-7}, & \text { if }(v \cdot n) \geq 2000, \\ f_{1} \cdot 160 \cdot d_{M}^{3} \cdot 10^{-7}, & \text { if }(v \cdot n)<2000,\end{cases}
$$

where $f_{1}$ represents the bearing factor for friction torque as a function of speed, $v$ denotes the kinematic viscosity of the ATF, $n$ is the operating speed, and $d_{M}$ denotes the mean bearing diameter. Consider

$T_{2}$

$$
=\left\{\begin{array}{l}
f_{2} \cdot P \cdot d_{M}, \\
\text { if ball, tapered roller and spherical roller bearings, } \\
f_{2} \cdot F \cdot d_{M}, \\
\text { if needle roller and cylindrical roller bearings, }
\end{array}\right.
$$

where $f_{2}$ represents the bearing factor for friction torque as a function of load, $P$ denotes the decisive load for friction torque, and $F$ represents the load for bearings. The total power loss of a bearing can be calculated as follows:

$$
P_{\text {loss_bearing }}=\left(T_{1}+T_{2}\right) \cdot 2 \cdot \pi \cdot n \text {. }
$$

2.1.3. Gear Meshing Loss. As shown in Figure 1, the 8AT used in this study has three planetary gear sets and four transfer gear sets. The loss of a planetary gear set is mainly a torque loss. The rolling power of the planetary gear generates losses in the teeth and planetary bearing. The loss of the planetary gear can be calculated as follows:

$$
P_{\text {loss_PG }}=T_{S} \cdot\left(\omega_{S}-\omega_{C}\right)+T_{R} \cdot\left(\omega_{R}-\omega_{C}\right),
$$

where $T_{S}$ denotes the torque of the sun gear, $T_{R}$ represents the torque of the ring gear, and $\omega_{S}, \omega_{R}$, and $\omega_{C}$ denote the angular speed of the sun gear, ring gear, and carrier. The kinetic relationship between $T_{S}$ and $T_{R}$ can be expressed as follows:

$$
T_{S} \cdot i_{0} \cdot \eta_{0}^{w}+T_{R}=0,
$$




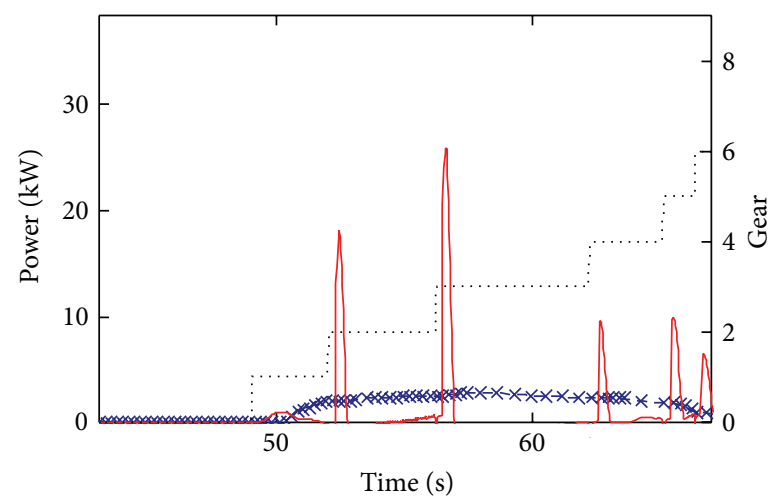

$-\rtimes$ - Sum of gear meshing and bearing loss

— Shifting loss

..... Gear

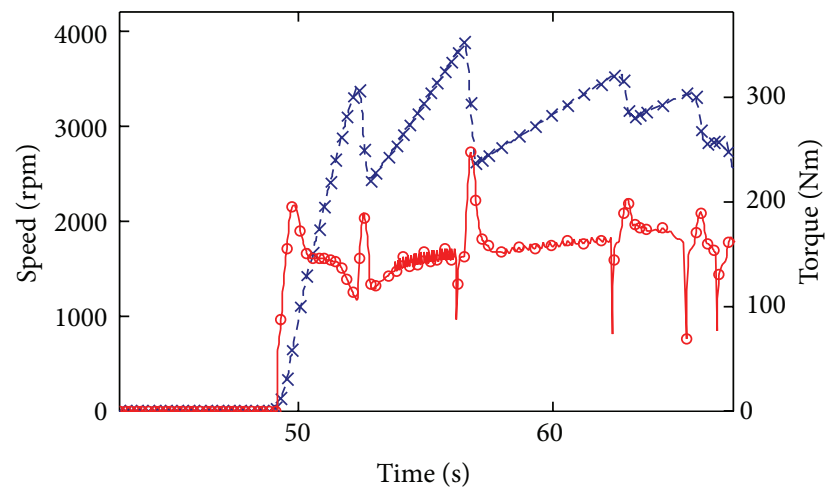

$-\nsucc$ - Input speed

$\rightarrow$ Input torque

FIgURE 3: Comparison of power losses in one driving cycle.

where $i_{0}$ represents the standard gear ratio, $w$ defines the direction of the power flow, and $\eta_{0}$ denotes the efficiency factor of a planetary gear set with a motionless carrier; it includes gear meshing efficiency and planetary bearing efficiency.

Equation (6) can also be applied to a transfer gear set where $T_{S}$ and $T_{R}$ can be replaced by the torque of the two meshing gears and $\omega_{C}$ can be set to zero. The total power loss of gear meshing can be calculated as follows:

$$
P_{\text {loss_gear }}=P_{\text {loss_PG }}+P_{\text {loss_TG }} \text {, }
$$

where $P_{\text {loss_TG }}$ denotes the loss of transfer gear.

Figure 3 illustrates the simulation results of different power losses in one driving cycle, indicating that the shifting loss is 2-6 times higher compared with the gear meshing and bearing losses, and the shifting loss accounts for most of the total mechanical power loss; the sum of gear meshing and bearing losses is mostly less than $5 \mathrm{~kW}$, according to (3)-(8); the gear meshing and bearing power losses are mainly influenced by the rotating speed and load. The simulation results indicate that the gear meshing and bearing power losses are high at a higher input speed and torque of transmission.
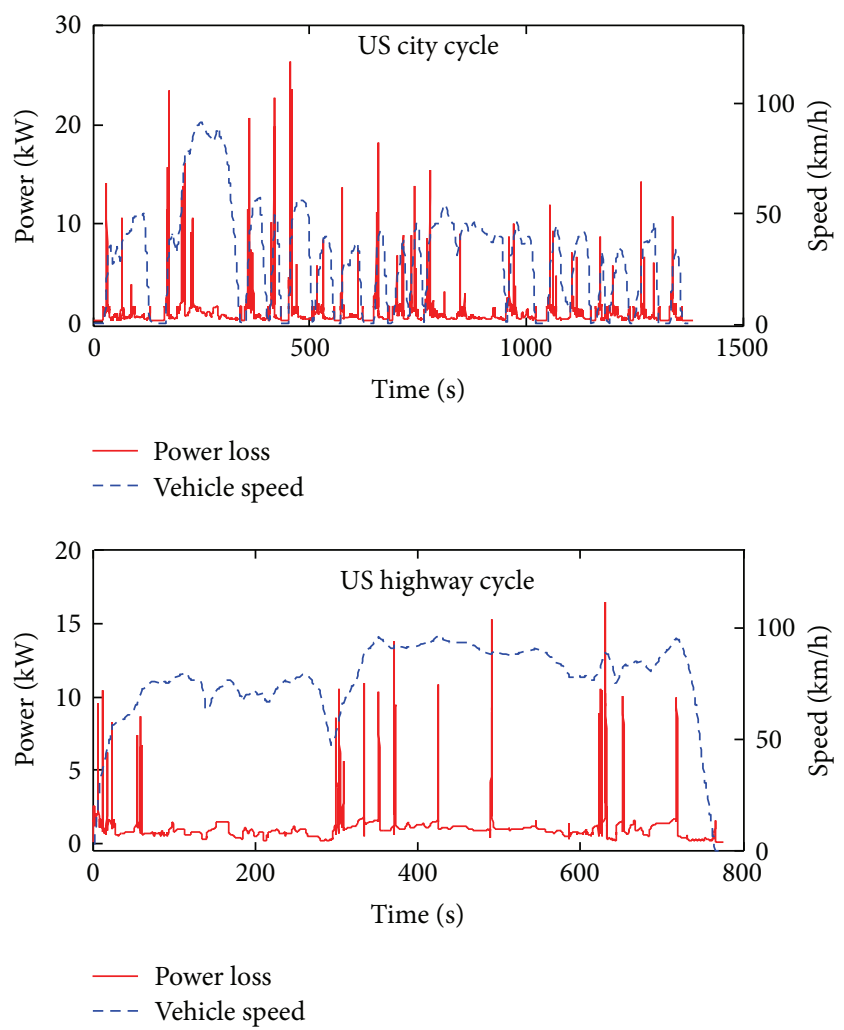

FIgURE 4: Mechanical power loss of the 8AT in city and highway cycles.

The total mechanical power loss is the sum of the shifting, bearing, and gear meshing losses. Consider

$$
P_{\text {loss_mech }}=\sum P_{\text {loss_shift }}+\sum P_{\text {loss_bearing }}+\sum P_{\text {loss_gear }} .
$$

Figure 4 shows the simulation results of the total mechanical power loss in two driving cycles, indicating that the total power loss in the city cycle is higher than that in highway cycle; the city cycle registered a higher number of peak losses compared with the highway cycle, the peak loss comprises mainly shifting loss, and this difference in the number of peak losses is because more shifting operations are performed under city conditions; the difference between the gear meshing and bearing loss in two cycles is extremely low. As shown in Figure 4, in the same cycle, the loss of power during acceleration is higher than that under constant speed. This phenomenon is because the input torque and speed are higher under acceleration than under constant speed.

2.2. Leakage Model. To maintain the line pressure when the engine stops, the EOP must compensate the leakage flow of the system. The leakage of AT mainly originates from the hydraulic unit. Figure 5 shows the hydraulic system of the 8AT used in this study; the detailed description of this system is provided in [12]. This system mainly has two types of valves-slide and solenoid valves-and both valves cause leakage. The leakage of the slide valve is caused by the gap between the spool and bore. Figure 6(a) shows a simplified 


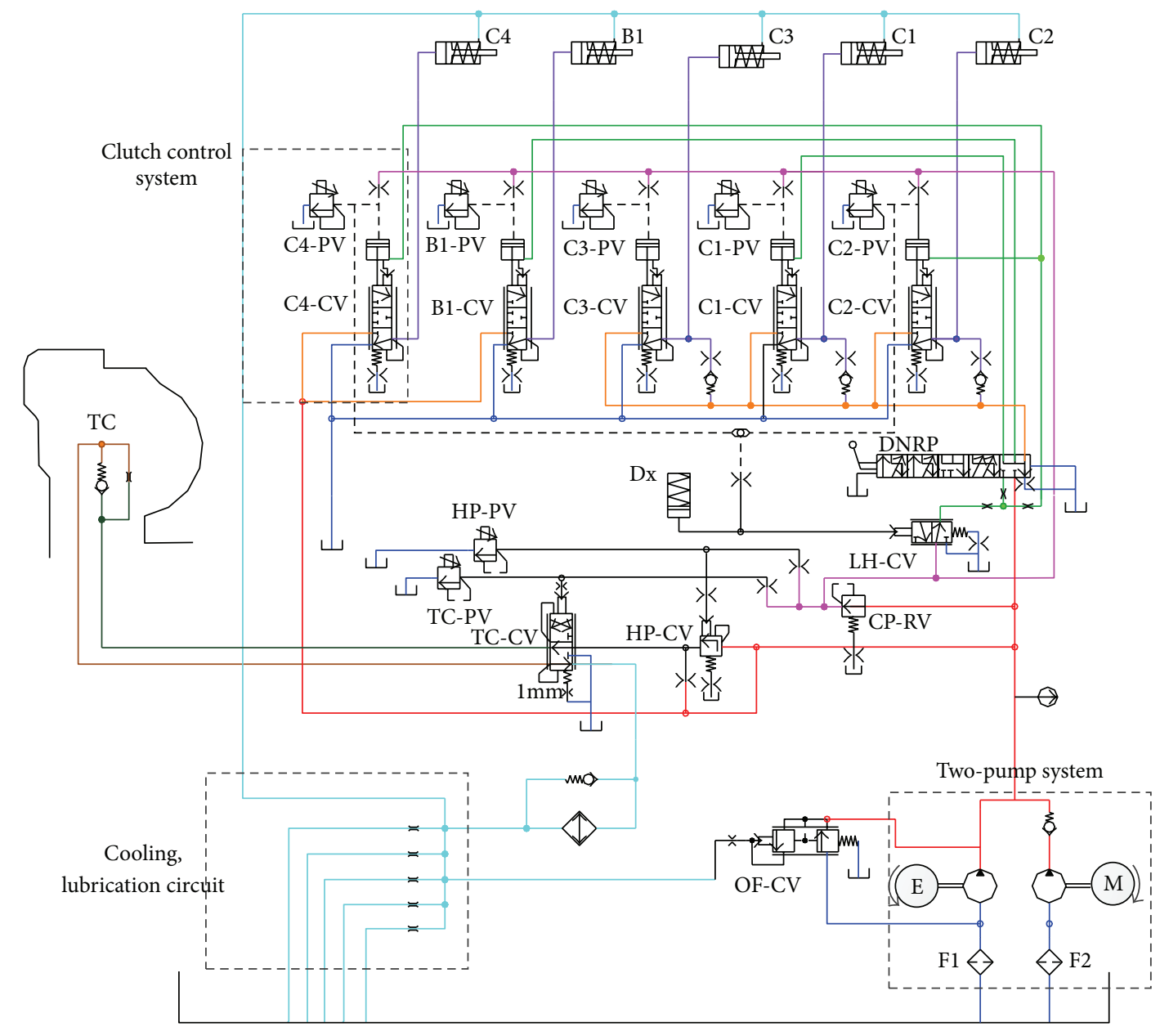

FIgURE 5: Schematic diagram of the 8AT hydraulic system.

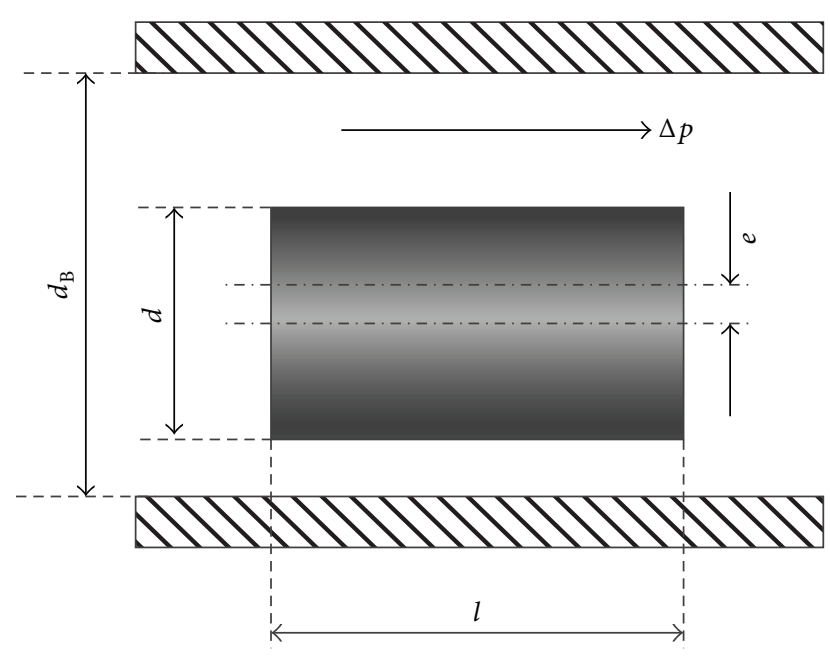

(a)

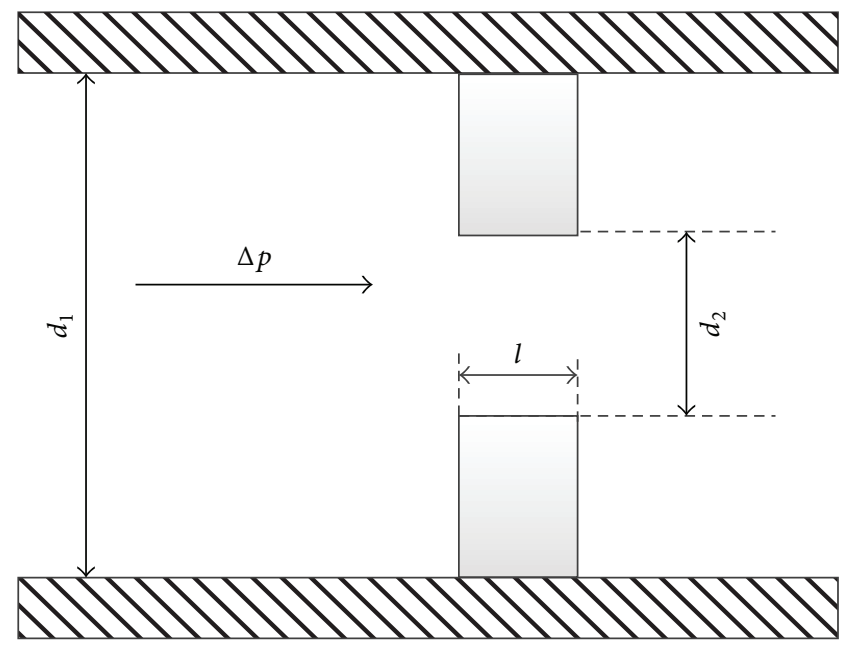

(b)

FIgURE 6: Two types of leakage in the hydraulic system. 


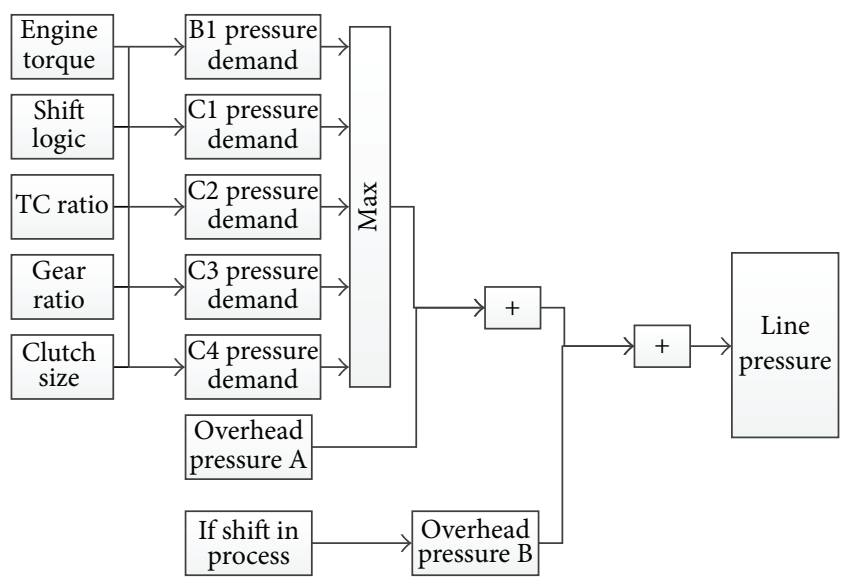

FIgURE 7: Line pressure control logic.

leakage model of this valve; this model is considered an eccentric ring gap leakage. All the seven solenoids of this system are electronic and proportional control valves that are normally open. The oil flows to the tank when the solenoid valve is open, thus leading to leakage. The leakage model of the solenoid valve can be considered an orifice leakage (Figure 6(b)).

The leakage flow of slide valve can be calculated as follows:

$$
Q_{\mathrm{sv}}=\frac{d \cdot \pi \cdot s^{3}}{12 \cdot v \cdot l \cdot \rho_{\mathrm{ATF}}} \cdot \Delta p \cdot\left(1+\frac{3}{2} \cdot \frac{e^{2}}{s^{2}}\right),
$$

where $d$ represents the diameter of the spool, $l$ denotes the overlap length of the bore and spool, $\Delta p$ is the pressure difference, $e$ represents the eccentricity, $s$ denotes the difference in radius between the bore and spool, $v$ represents the kinematic viscosity of the ATF, and $\rho_{\text {ATF }}$ is the density of the ATF.

The leakage flow of solenoid valve can be calculated as follows:

$$
Q_{\text {sld }}=\alpha_{D} \cdot A_{0} \cdot \sqrt{\frac{2 \cdot \Delta p}{\rho_{\text {ATF }}}},
$$

where $\alpha_{D}$ represents the flow coefficient and $A_{0}$ denotes the cross-sectional area of orifice.

In the calculations, the eccentric is assumed as the maximum tolerance $\left(d_{B}-d\right) / 2$, and the pressure difference between the slide valves can be considered the line pressure. The difference in pressure of the solenoid valve varies from 0 to 5 bar, depending on the control current. This phenomenon is because a pressure reduction valve "CP-RV" in the hydraulic system limits the solenoid pressure to 5 bar. Equations (10) and (11) indicate that the leakage flow of the system is highly influenced by the line pressure and ATF temperature. The line pressure control and temperature-viscosity characteristic were integrated into the simulation model as follows.

2.2.1. Line Pressure Control. The line pressure is controlled according to the system requirements to reduce the loss of hydraulic power. Figure 7 shows the line pressure control logic. The pressure demand for each clutch can be calculated

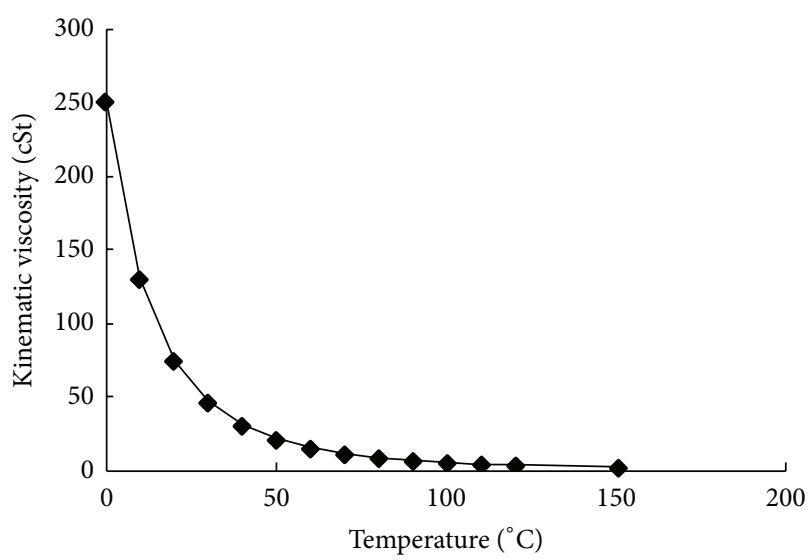

FIGURE 8: Temperature-viscosity characteristic.

in time according to the engine torque, torque converter ratio, shift logic, gear ratio, and data of the clutch size. A higher clutch pressure is required for delivering a higher torque. When an overhead pressure $\mathrm{A}$ is added to the maximal pressure demand, the clutch pressure is equal to the line pressure demand. If a shifting is processing another overhead pressure B will be added to the line pressure demand again; this is performed to prevent the effect of pressure drop during clutch filling.

2.2.2. Temperature-Viscosity Characteristic. The kinematic viscosity $v$ is highly influenced by the temperature of the ATF. According to [13], the relationship between viscosity and temperature is expressed by (12). The temperature-viscosity characteristic can be interpolated according to two known viscosity values at corresponding temperatures. Figure 8 shows the interpolation results of the temperature-viscosity characteristic, and the viscosity of ATF decreases with the temperature rising; this characteristic was integrated into the simulation model. Consider

$$
\log \log (\nu+0.7)=a+b \times \log T .
$$

The system leakage flow is the sum of the two leakage types:

$$
Q_{\text {Leakage }}=Q_{\text {sv }}+Q_{\text {sld }} \text {. }
$$

The leakage model was put into operation in the NEDC cycle under a normal AT working temperature of $90^{\circ} \mathrm{C}$. Figure 9 shows the simulation results, indicating that the leakage flow is considerably influenced by line pressure under a constant temperature; the line pressure increases with the vehicle acceleration due to more delivering torque; the total leakage increases with the line pressure because, according to (10), the leakage of the slide valves increases with the line pressure. The leakage flow of the system is also considerably influenced by the solenoids control. The simulation results shown in Figure 9 indicate that the leakage under a neutral gear condition is higher than those under other gear conditions. This phenomenon is because, under a neutral gear condition, only two clutches are engaged and only two solenoids are closed (B1-PV and C4-PV); however, the other five 


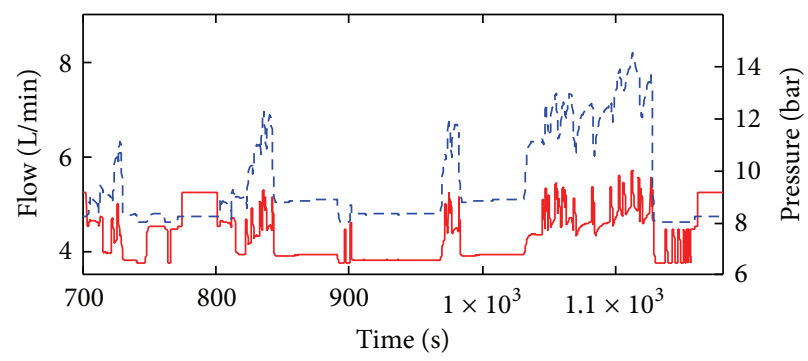

- Total leakage - - - Line pressure

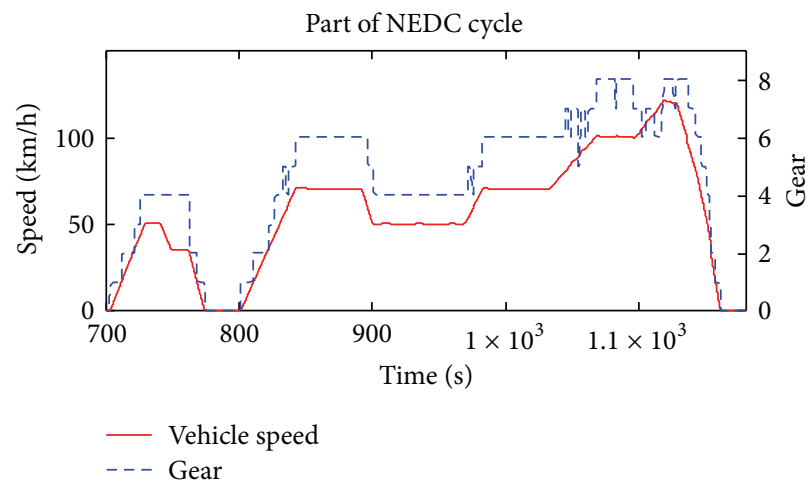

FIGURE 9: Simulation results of leakage flow in the NEDC cycle.

solenoids are open, thus leading to more leakage. In addition, the leakage at low vehicle speeds is higher than at high vehicle speeds. This phenomenon is because, at low vehicle speeds, the torque converter must be open to increase the driving torque, and the torque converter lock-up control solenoid "TC-PV" is open, thus leading to more leakage.

\section{Flow-Based Control Algorithm of EOP}

3.1. Flow Requirement of EOP. To satisfy the start-stop function and support the MOP to supply flow at low engine speeds, this study developed a flow-based control algorithm of the EOP. This control algorithm can be divided into three phases.

Phase A. When the engine stops, the EOP operates at a low speed to compensate the leakage flow. The EOP output flow can be expressed as follows:

$$
Q_{\text {EOP_A }}=Q_{\text {Leakage }} \text {. }
$$

Phase $B$. When the engine is being restarted, the EOP operates at a high speed for the leakage and clutch filling. The EOP output flow can be expressed as follows:

$$
Q_{\text {EOP_B }}=Q_{\text {Leakage }}+Q_{\text {Fill }}=Q_{\text {Leakage }}+\frac{V_{c}}{t_{\text {Fill }}},
$$

where the $Q_{\text {Fill }}$ represents the flow of clutch filling, $V_{c}$ denotes the volume of the clutch, and $t_{\text {Fill }}$ is the clutch filling time.

Phase C. After the vehicle starts, the EOP operates to support the MOP to provide lubrication and cooling at low engine

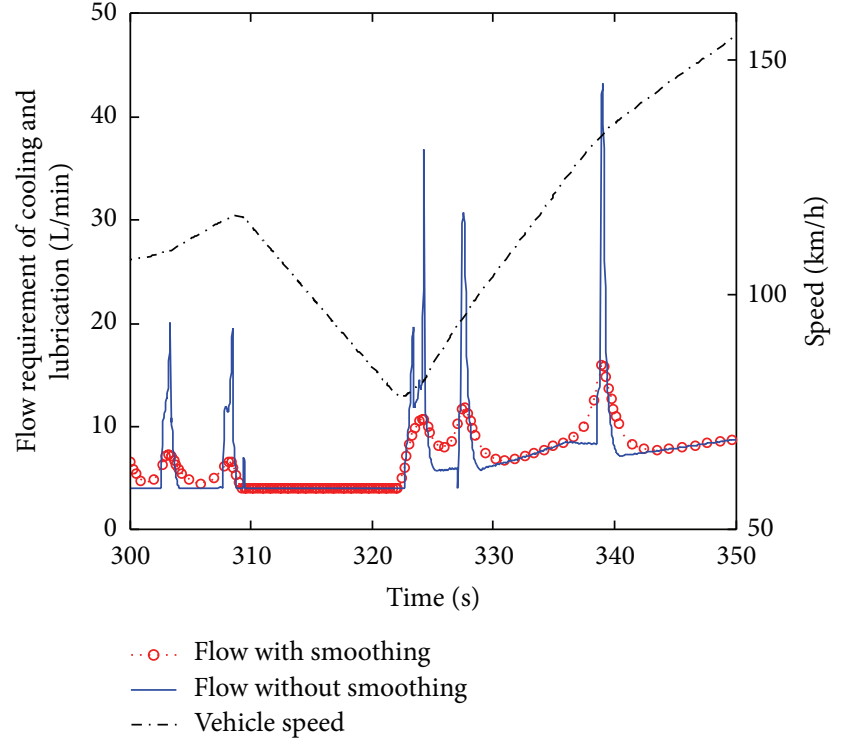

FIGURE 10: Smooth function for the flow requirement.

speeds. The output flow of the EOP depends on the flow requirement of the system and output flow of the MOP. The flow requirement of the system is the sum of cooling, lubrication flow, and leakage flow. The flow requirement for cooling and lubrication can be calculated as follows:

$$
Q_{\text {cooling }}=\frac{c_{\text {cooling }} \cdot P_{\text {loss_mech }}}{c_{\mathrm{ATF}} \cdot \rho_{\mathrm{ATF}} \cdot \Delta T}
$$

where $c_{\mathrm{ATF}}$ represents the heat capacity of the ATF, $\Delta T$ denotes the permissible increase in temperature of the ATF, and $c_{\text {cooling }}$ represents a factor that defines the proportion of heat dissipated by the ATF; it was set to $90 \%$ by assuming that $10 \%$ heat is dissipated by housing. Figure 10 illustrates the simulation results of the cooling and lubrication flow requirement in one driving cycle, indicating that the cooling flow requirement increases markedly during each shifting. This increase is because the power loss of shifting is much higher than the other power losses, as highlighted previously. However, in real-world situations, the heat generated in such a short time cannot be dissipated by the oil immediately. In addition, the output flow of the EOP cannot fluctuate so sharply to meet the cooling and lubrication requirement. Therefore, a first order time delay function was used to smooth the flow requirement. As shown in Figure 10, although the total volume of flow requirement is not changed after smoothing, the peaks were smoothed for actual applications.

The system flow requirement is the sum of cooling and leakage:

$$
Q_{\text {sys }}=\max \left(Q_{T C}, Q_{\text {cooling_PT1 }}+Q_{\text {Leakage }}\right),
$$

where $Q_{\mathrm{TC}}$ represents the minimal flow requirement for the torque converter to maintain normal operation. $Q_{\text {cooling_PT1 }}$ denotes the smoothed flow requirement of cooling and 


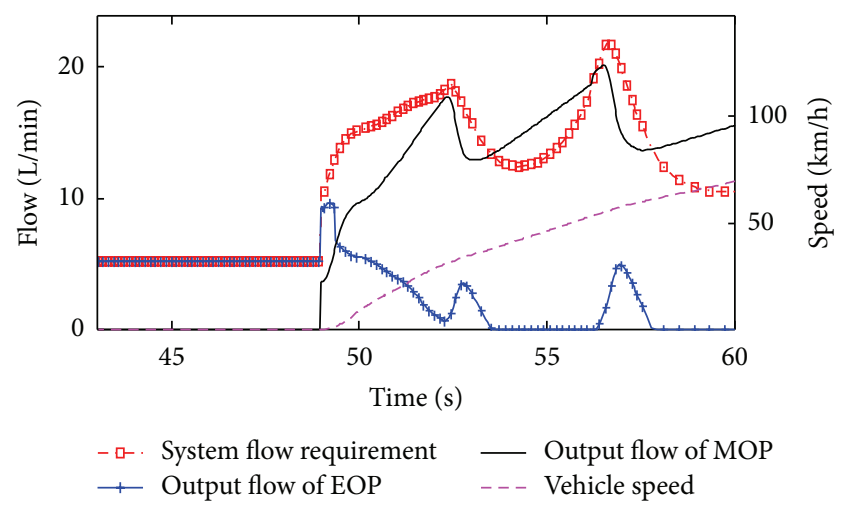

FIGURE 11: Simulation results of the output flow in a driving cycle.

lubrication. The flow that must be supplied by the EOP can be derived by subtracting the output flow of the MOP from the total flow requirement of the system:

$$
\mathrm{Q}_{\mathrm{EOP} \_\mathrm{C}}=Q_{\text {sys }}-Q_{\mathrm{MOP}}=Q_{\text {sys }}-n_{e} \cdot V_{\mathrm{MOP}} \cdot \eta_{\mathrm{MOP} \_ \text {vol }} \text {, }
$$

where $V_{\text {MOP }}$ represents the displacement of the MOP, $\eta_{\text {MOP_vol }}$ denotes the volumetric efficiency of the MOP, and $n_{e}$ represents the engine speed. Figure 11 shows the simulation results of the operating process in driving cycle of this two-pump system; the size of the MOP was reduced to $10 \mathrm{~mL}$. As shown in Figure 11, when the vehicle stops, the EOP operates on its own to compensate the leakage by outputting the flow of approximately $5 \mathrm{~L} / \mathrm{min}$; when the vehicle tends to start, the EOP increases its output flow to guarantee the filling of the forward clutch. Furthermore, when the vehicle accelerates, the flow requirement of the system increases and according to (18), the output flow of the MOP also increases when the vehicle accelerates. In some engine speed ranges, the EOP supports the MOP to meet the requirement of the system; however, when the engine runs at a certain speed and the MOP can satisfy the flow requirement of the system on its own, the EOP shuts off. Once the speed of the engine drops and the MOP cannot satisfy the system requirement on its own, the EOP switches on to support the MOP. The simulation results indicated that the flow-based control algorithm of EOP adequately satisfied the flow requirement and reduced the energy consumption to the lowest level at the same time.

3.2. Heat Transfer Model of Shifting Element. High temperature is one of the primary causes of wet clutches system deterioration and failure. Supplying enough oil flow to the shifting elements is extremely crucial. According to [14], 90\% of the generated heat is absorbed by the steel plate of the clutch pack. To achieve an optimal cooling effect for the shifting elements with the two-pump system, a heat transfer model between the ATF and steel plate was established. The heat transfer model created provides support to optimize the EOP control algorithm. The heat transfer coefficient between the ATF and steel plate for the open clutch is influenced by several factors and can be obtained only from tests. The heat transfer coefficient for a closed clutch can be calculated as follows:

$$
\partial=\frac{\mathrm{Nu} \cdot \lambda_{\mathrm{ATF}}}{d_{h}}
$$

where $\lambda_{\text {ATF }}$ represents the heat transfer coefficient of the ATF, $d_{h}$ denotes the hydraulic diameter of the slot in the friction plate, and $\mathrm{Nu}$ is a factor that can be calculated as follows:

$$
\mathrm{Nu}=\frac{(\zeta / 8) \cdot \operatorname{Re} \cdot \operatorname{Pr}}{1+12.7 \sqrt{\zeta / 8} \cdot\left(\operatorname{Pr}^{2 / 3}-1\right)},
$$

where Re denotes the Reynolds number of the ATF, Pr represents the Prandtl number of the ATF, and $\zeta$ is the friction factor of the gallery and it can be calculated as follows:

$$
\zeta=\frac{1}{(1.8 \cdot \log (\mathrm{Re})-1.5)^{2}} .
$$

The rate of the temperature change of the steel plate can be calculated as follows:

$$
T_{\text {se }}^{\prime}(t)=\frac{P_{\mathrm{C} x}(t)-\left(T_{\mathrm{se}}(t)-T_{\mathrm{ATF}}\right) \cdot \alpha(t) \cdot A_{c}(t)}{c_{\text {steel }} \cdot m_{\text {se }}},
$$

where $P_{C x}(t)$ represents the power loss of the shifting element as calculated in (2), $T_{\text {se }}(t)$ denotes the temperature of the steel plate, $T_{\mathrm{ATF}}$ represents the temperature of the ATF, and $\alpha(t)$ is the heat transfer coefficient between the steel plate and ATF; for a closed clutch, this coefficient is calculated by (19) and for an open clutch, it is set to a constant according to [15]. Furthermore, $A_{c}(t)$ represents the contact area between the ATF and steel plates, $c_{\text {steel }}$ denotes the heat transfer factor of the steel plate, and $m_{\text {se }}$ is the mass of the steel plate. The temperature of the steel plate can be obtained by solving this ordinary differential equation. Figure 12 shows the simulation results of the temperature of the $\mathrm{C} 1$ steel plates under an extreme condition of a US race cycle. The vehicle accelerates and decelerates sharply in this cycle, requiring extremely high delivering torques and numerous shifting operations. The initial temperature of $\mathrm{C} 1$ steel plates was set to $120^{\circ} \mathrm{C}$ in simulation, which is the highest temperature for normal operation of the ATF. The results illustrated in Figure 12 indicate that the heat generated during shifting cannot be dissipated instantaneously by the ATF oil; the heat stress decreased gradually after each shifting by the cooling of the ATF. The maximal temperature of $\mathrm{Cl}$ steel plate was less than $200^{\circ} \mathrm{C}$ even in this extreme driving condition; the steel plate must be able to bear such a high temperature. Simulation results proved that the $8 \mathrm{AT}$ can work well with the two-pump system.

The output flow of the EOP depends on the flow requirement of the system. However, in reality, the EOP would shut off too early if it operates in unison with the flow demand. To support sufficient flow, this study developed a shut-off delay control of the EOP. The shut-off delay time depends on the size of the flow requirement. Figure 13 illustrates the control logic and its effect on cooling the shifting element in the simulation. The principle of the delay control is that 

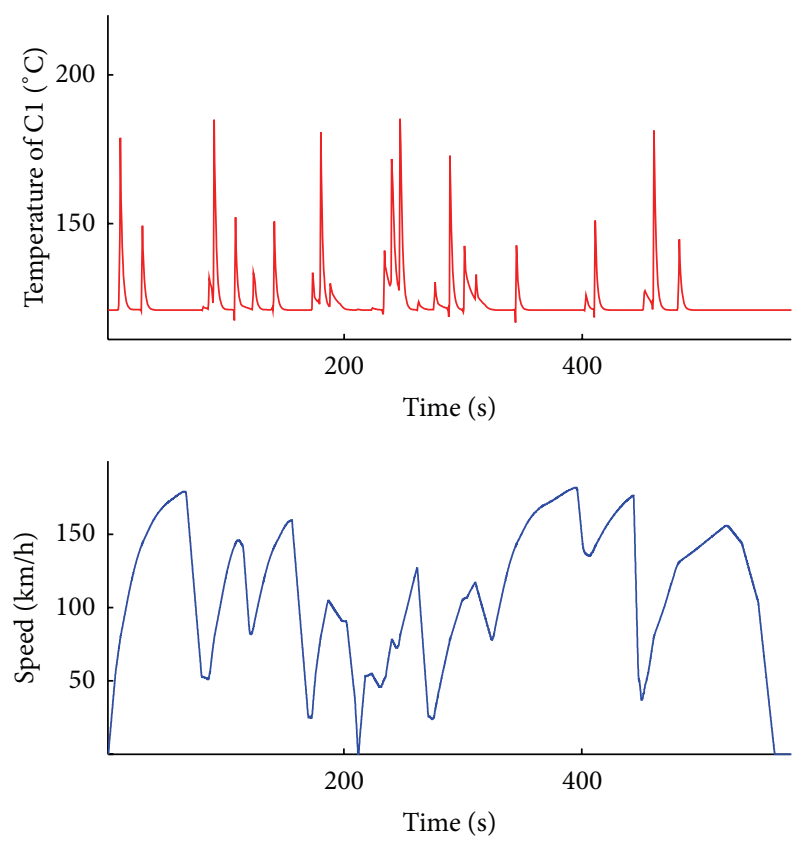

FIgURE 12: Temperature of $\mathrm{Cl}$ in the US race cycle.
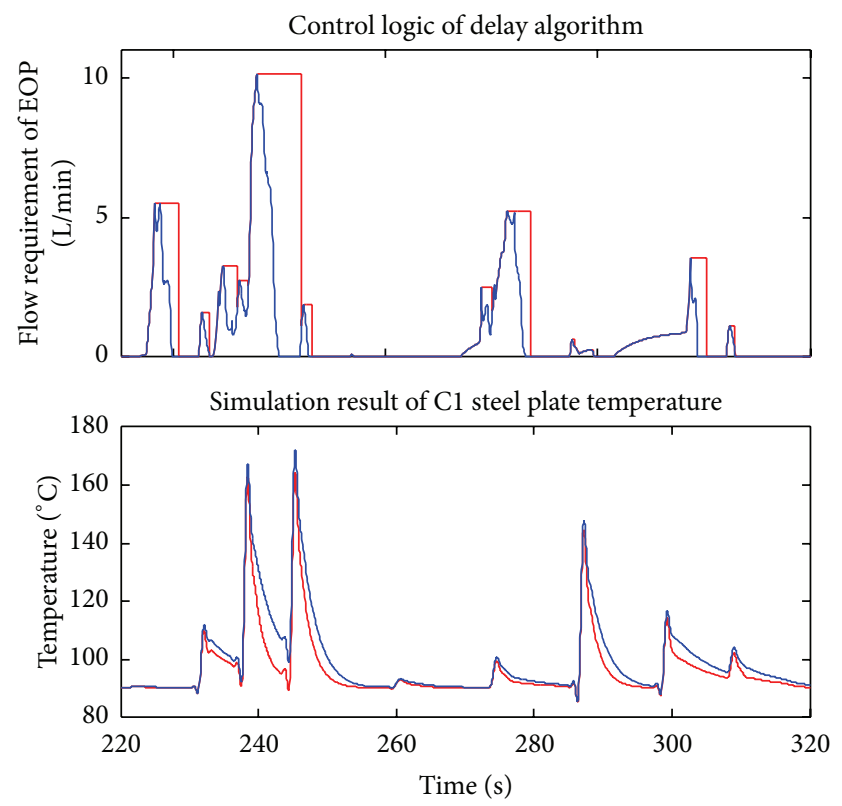

With delay control

— Without delay control

FIGURE 13: Simulation result of delay control of EOP.

the EOP shut-off delay time increases as the flow requirement increases. The simulation results shown in Figure 13 indicate that the peak value of the temperature is nearly the same, regardless of the delay control; however, when the delay control was used, the temperature decreased faster compared with the simulation with no delay control. This implies that the steel plates can be cooled faster with delay control. This control method can benefit the working durability of shifting elements.

3.3. Control Method of EOP. The developed flow-based control algorithm of the EOP was integrated into the TCU. The EOP has its own controller. The rotating speed of the EOP can be controlled through CAN communication between the TCU and EOP controller. The speed of the EOP is expressed as follows:

$$
n_{\mathrm{EOP}}=\frac{Q_{\mathrm{EOP}}}{V_{\mathrm{EOP}} \cdot \eta_{\mathrm{EOP} \_ \text {vol }}},
$$

where $Q_{E O P}$ represents the output flow of the developed control algorithm, $V_{\mathrm{EOP}}$ denotes the displacement of the EOP, and $\eta_{\text {EOP_vol }}$ represents the volumetric efficiency of the EOP. The volumetric efficiency of oil pumps varies depending on the speed, pressure, and temperature. In (18) and (23), $\eta_{\text {EOP_vol }}$ and $\eta_{\text {MOP_vol }}$ are variables obtained through tests.

\section{Effect of Pump Selection on Fuel Economy}

For this study's two-pump system, different MOP and EOP combinations consume a different amount of energy. The total energy consumption of the two-pump system can be calculated as follows:

$$
\begin{aligned}
E_{\text {total }} & =\int\left(P_{\mathrm{MOP}}+P_{\mathrm{EOP}}\right) \cdot t \cdot d t \\
& =\int\left(\frac{p_{\text {line }}(t) \cdot Q_{\mathrm{MOP}}(t)}{\eta_{\mathrm{MOP}}(t)}+\frac{p_{\text {line }}(t) \cdot \mathrm{Q}_{\mathrm{EOP}}(t)}{\eta_{\mathrm{EOP}}(t)}\right) \cdot t \cdot d t,
\end{aligned}
$$

where $P_{\mathrm{MOP}}$ and $P_{\mathrm{EOP}}$ represent the power of the MOP and EOP; $p_{\text {line }}$ denotes the system line pressure; $\eta_{\mathrm{MOP}}$ is the total efficiency of the MOP, including volume and mechanical efficiency; and $\eta_{\mathrm{EOP}}$ is the total efficiency of the EOP, including volume, mechanical, and electrical efficiency. Depending on the working condition, $\eta_{\mathrm{MOP}}$ and $\eta_{\mathrm{EOP}}$ are both variables. The power of the EOP depends on the displacement of the MOP; it decreases as the displacement of the MOP increases. The total energy consumption at various displacements of the MOP and in different typical cycles was calculated by simulation method. Figure 14 illustrates the simulation results of total energy consumption, indicating that, in most cycles, a $7 \mathrm{~mL}$ MOP displacement is the optimal solution, and the power demand of the EOP in this solution is $600 \mathrm{~W}$. The waste of power of the MOP can be reduced by decreasing the MOP displacement. However, an MOP with an extremely low displacement is not the most efficient solution because the energy consumption of the EOP tends to increase. The total efficiency of the EOP was higher than that of the MOP because of the electrical efficiency of the EOP. Therefore, the MOP must be maintained and a combination of both pumps is the most efficient solution. The simulation results indicated that the optimal combination is a $7 \mathrm{~mL} \mathrm{MOP}$ and $600 \mathrm{~W}$ EOP. In a real-world application, considering the constraint of the EOP working durability and space arrangement, a $10 \mathrm{~mL}$ MOP and $400 \mathrm{~W}$ EOP were used. Figure 15 shows 


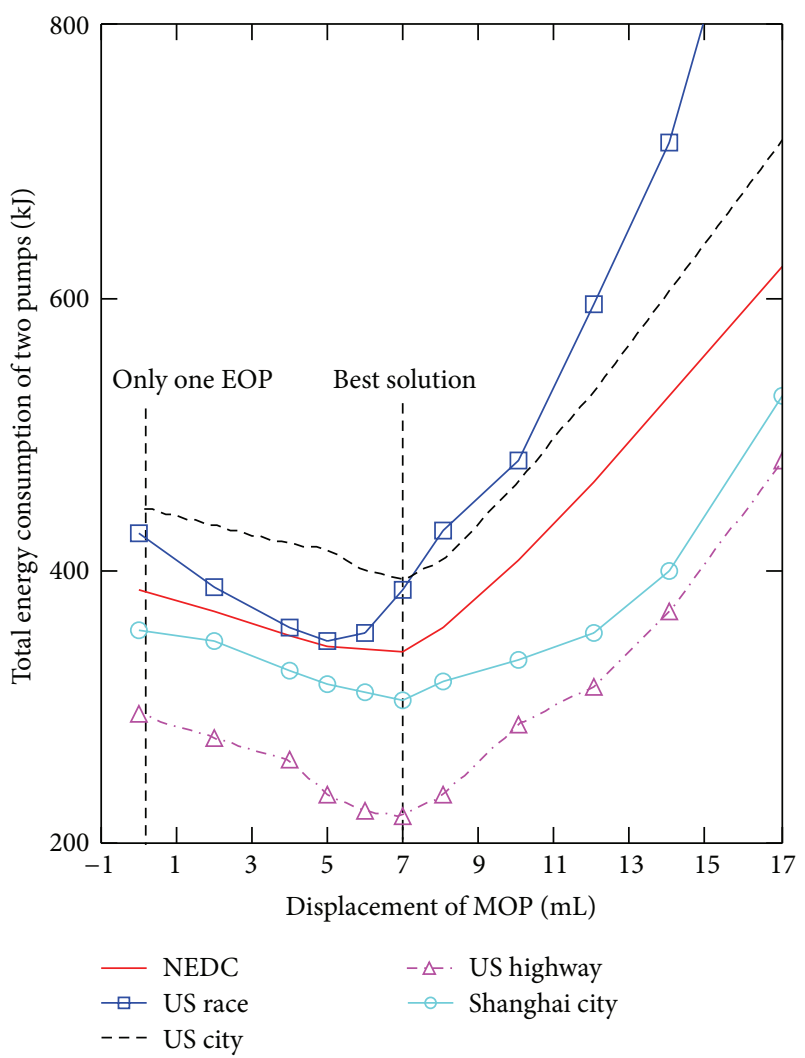

FIGURE 14: Energy consumption in different driving cycles.

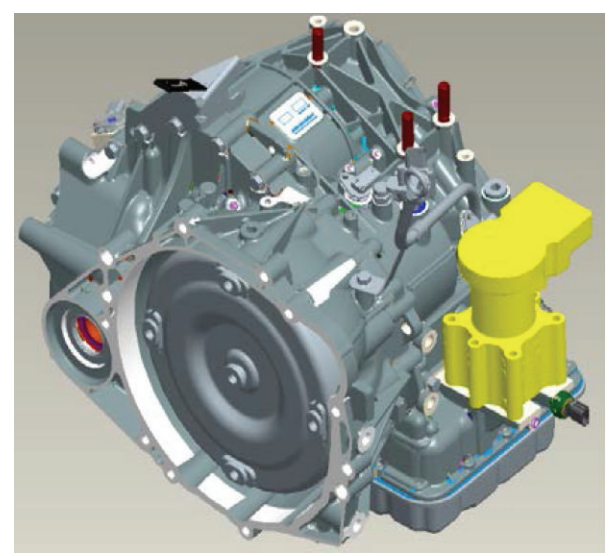

Figure 15: Layout of the EOP in 8AT.

the layout of the EOP used in this study's 8AT; the EOP comprises a BLDC motor, an external gear pump, and a controller; this layout synthetically considered the interference in vehicle body, suction and discharge port, filter, oil circuit, and modification cost. The EOP is placed near the oil tank and hydraulic block to reduce the hydraulic loss in the circuit.

As shown in Figure 14, the two-pump system can reduce the energy consumption by approximately $40 \%$ compared with the single MOP system. The proportion of the improvement in fuel economy achieved by the two-pump system

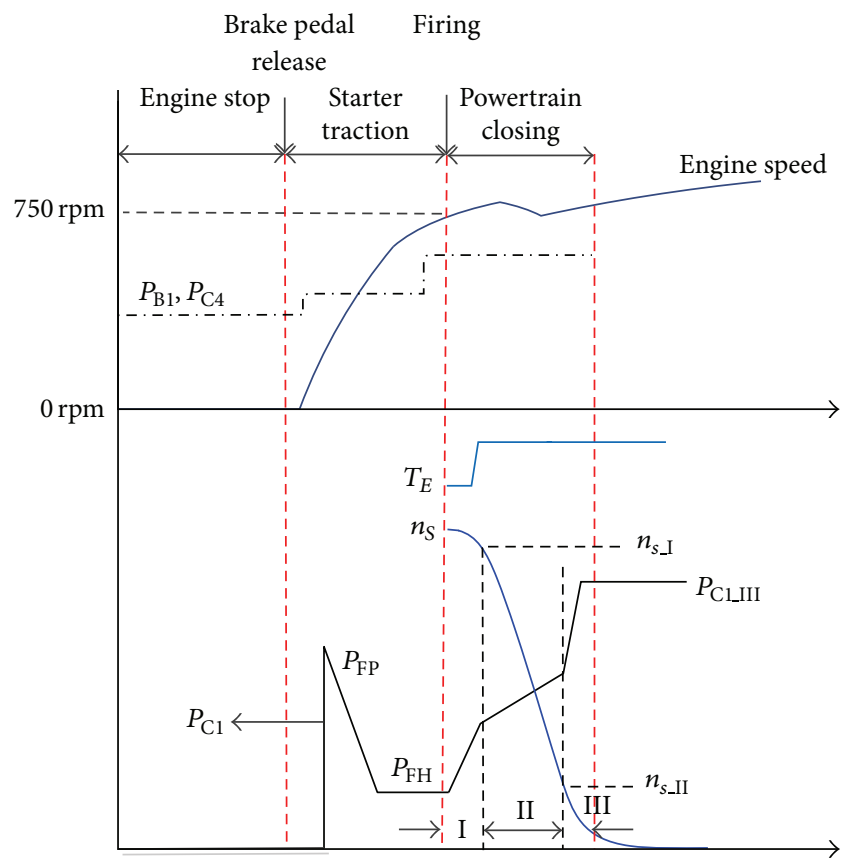

FIGURE 16: Control logic of starting clutch.

compared with the single MOP system can be evaluated as follows:

$$
\eta_{\mathrm{FE}}=\frac{E_{\text {onlyMOP }}-E_{\text {total }}}{E_{\text {eng }}}=\frac{E_{\text {onlyMOP }}-E_{\text {total }}}{\int 2 \cdot \pi \cdot n_{e}(t) \cdot T_{e}(t) \cdot t \cdot d t},
$$

where $E_{\text {onlyMOP }}$ represents the energy consumption of single MOP system calculated in the same manner as $E_{\text {total }}, E_{\text {eng }}$ denotes the energy outputted by the engine, and $n_{e}$ and $T_{e}$ represent the speed and torque of the engine, respectively.

A simulation was performed in the NEDC cycle and the results indicated that the two-pump system achieved a fuel improvement of $2.4 \%$ compared with the conventional single MOP system. When the $5 \%$ fuel improvement achieved by the start-stop function was added, the vehicle containing the $8 \mathrm{AT}$ of two-pump system achieved a total fuel improvement of $7.4 \%$.

\section{Starting Clutch Control Strategy}

In this study, the engine was restarted with an open powertrain to prevent the starter from operating with a high load. For the AT-based vehicle, the start-stop function operated normally in the selector position "D." The TCU controlled the automatic opening and closing of the powertrain during the start-stop process. Signals were communicated between the EMS (engine management system) and TCU through the CAN. Before the engine shuts off, the EMS requests the TCU to open the powertrain. The powertrain must be closed quickly when the engine restarts. Figure 16 illustrates the control logic of the starting clutch, and it can be divided into 
three phases: engine stop, starter traction, and powertrain closing.

Engine Stop Phase. With the facilitation of the EOP, the hydraulic line pressure can be supplied and the neutral gear clutches B1 and C4 can be engaged. The pressure of the B1 and C4 was set to a pressure that is just higher than each kisspoint, instead of a pressure of the completely closed clutch; this can reduce the line pressure demand, thus reducing the EOP power consumption. The $\mathrm{Cl}$ is kept open to prevent the engine from restarting with the vehicle load.

Starter Traction Phase. In this phase, the starter cranks the engine to idle speed. The pressure of the B1 and C4 was set to increase gradually up to a pressure level that is sufficient for the clutch to close. The $\mathrm{C} 1$ is controlled to enter into the fill phase and a triangle fill type is used. $P_{\mathrm{FP}}$ represents the command pressure of rapid fill and $P_{\mathrm{FT}}$ denotes the holding pressure after filling. In this phase, the starter operates with little load and $\mathrm{C} 1$ is already prepared to deliver the torque.

Powertrain Closing Phase. This phase is actually the speed phase of the $\mathrm{Cl}$. The $\mathrm{Cl}$ can be controlled through two methods. The first method is a PI closed loop control based on the clutch slip, and the second method is an open loop control for the pressure increase gradient. To accomplish a quick and smooth torque delivery, the $\mathrm{C} 1$ speed phase was divided into three processes as follows.

(I) $\mathrm{Cl}$ starts to transmit torque after filling. The engine increases the output torque $T_{E}$ when the EMS receives the request from the TCU for an increased torque. The purpose of this process is to reduce the clutch slip from $n_{S}$ to $n_{s \text { I }}$ stably, which is a calibrated value. The $\mathrm{Cl}$ command pressure $P_{\mathrm{C} 1}(n)$ can be expressed as follows:

$$
\begin{aligned}
P_{\mathrm{C} 1}(n)= & P_{\mathrm{C} 1}(n-1)+\Delta P_{\mathrm{C} 1 \_I_{\mathrm{I}}}\left(n_{S}(n)\right) \\
& +k_{P} \cdot\left[n_{S}(n)-n_{S_{\text {_target }}}(n)\right] \\
& +k_{I} \sum_{n=1}^{n}\left[n_{S}(n)-n_{S_{-} \text {target }}(n)\right],
\end{aligned}
$$

where $\Delta P_{\mathrm{C} 1 \_}\left(n_{S}(n)\right)$ represents the rate of change of the target pressure that is related to clutch slip, $k_{P}$ and $k_{I}$ are the proportion and integration control parameter of target pressure, respectively, and $n_{S_{-} \text {target }}$ denotes the target clutch slip.

(II) This process is to continue reducing the clutch slip of $\mathrm{Cl}$ by increasing the control pressure, eventually realizing the speed synchronization. The command pressure is the same as that shown in (26), except for the PI control parameters. Process II ends at the $n_{S_{-} \text {II }}$ clutch slip, which can be calibrated.

(III) This process is performed to increase the $\mathrm{Cl}$ control pressure to $P_{\mathrm{C} 1 \text { _III }}$, which keeps the clutch totally

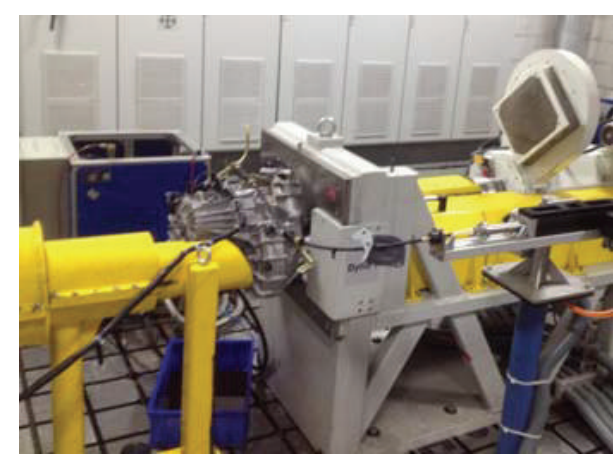

FIGURE 17: Setup of the rig test.

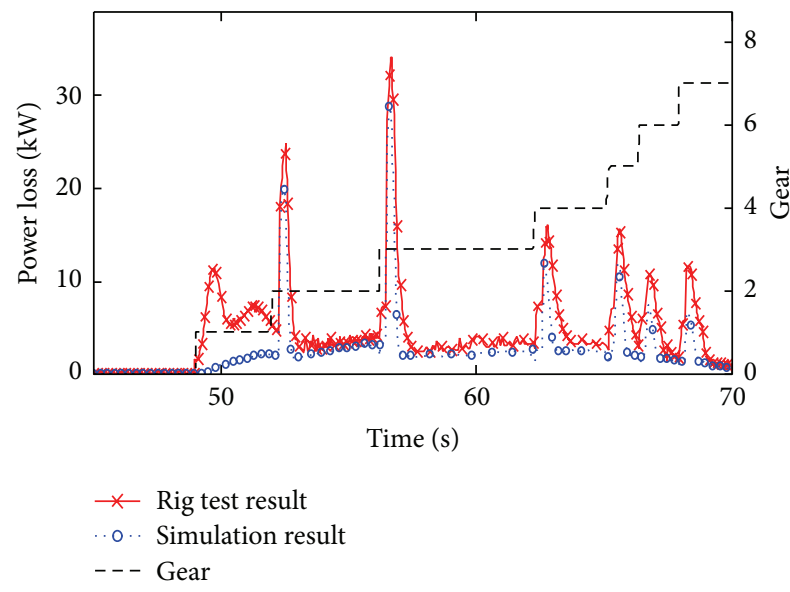

FIGURE 18: Rig test results of power loss.

closed. The command pressure of $\mathrm{Cl}$ can be expressed as follows:

$$
P_{\mathrm{C} 1}(n)=P_{\mathrm{C} 1}(n-1)+\Delta P_{\mathrm{C} 1 \_\mathrm{III}},
$$

where $\Delta P_{\mathrm{C} 1 \text { III }}$ denotes the rate of change of the $\mathrm{C1}$ target pressure.

\section{Test Verification}

A rig test was used to verify the power loss model. Figure 17 shows a GIF $3 \mathrm{E}$ test rig (one driving motor and two load motors), one motor was linked to the input side of the transmission acting as engine, and the other two motors were linked to the output side of the transmission acting as vehicle load. The speed and torque of each motor can be obtained from the rig dynamometers. This rig can accomplish a dynamic test of transmission by running in defined cycles. Figure 18 illustrates the results of the rig test performed in a dynamic test cycle. The power loss of the 8AT can be evaluated by calculating the difference between the input power and output power of the transmission. The loss of power during shifting was much higher than that with no shifting. The power loss of the test data was always slightly higher than that of the simulation results because the power loss from the test data also contains the hydraulic loss and 


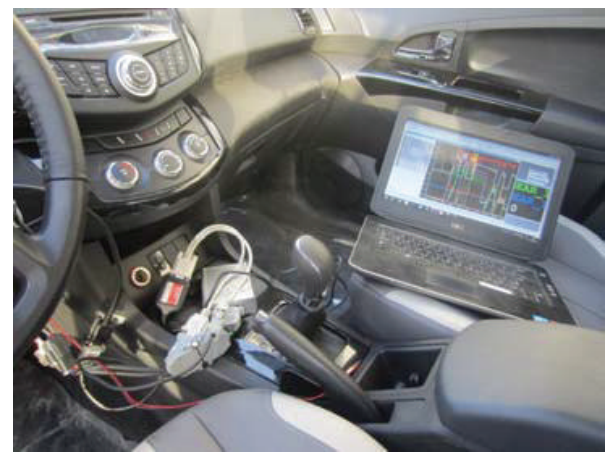

FIGURE 19: Setup of vehicle test.

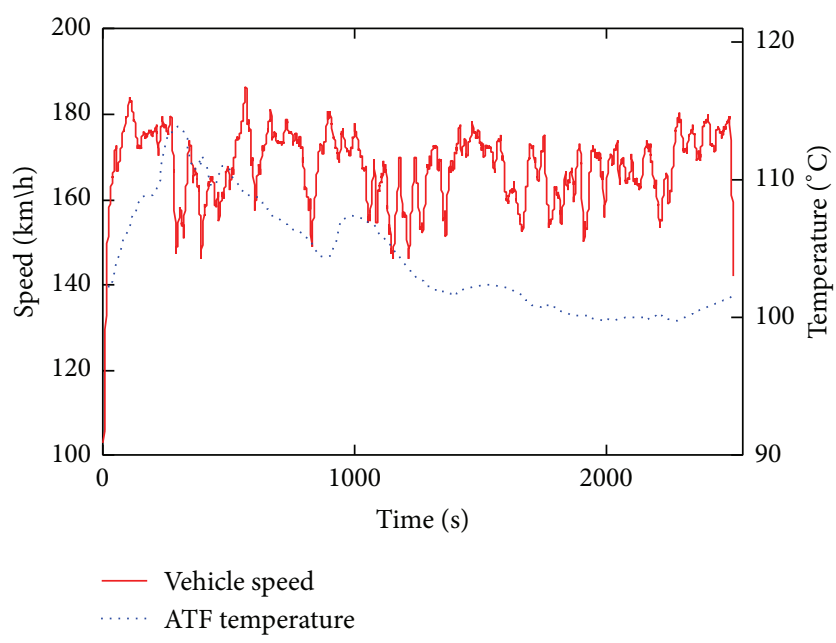

FIGURE 20: Vehicle test of high temperature.

electric loss; the difference between test data and simulation results is extremely obvious in low gears because of the torque converter opening; the torque converter generates a big hydraulic power loss when it works in the hydraulic condition. On the whole the test data were consistent with the simulation results. Figure 19 shows the vehicle test setup. A prototype vehicle equipped with an 8AT of the proposed twopump system was established, and the flow-based control algorithm and starting clutch control strategy were integrated into the TCU. All the test data were based on the CANape12.0 software and CANcase hardware. Figure 20 shows the hightemperature test results of the vehicle at a high acceleration. The ATF temperature increased because of the heat generated by frequent accelerations and numerous shifting operations. The maximal temperature of ATF was less than $115^{\circ} \mathrm{C}$, and it was always maintained at a normal level $\left(90-120^{\circ} \mathrm{C}\right)$; no parts failed because of heat stress. The test results indicated that the two-pump system can supply sufficient oil flow for cooling and lubrication. Figure 21 shows the test results of the vehicle start. When the engine stopped, the line pressure was maintained by the EOP and then B1 and C4 were engaged in preparation. No noise was heard in the cockpit because the EOP just worked in low speed for leakage compensation. B1 was slightly engaged with the pressure 3 bar; no clutch slip
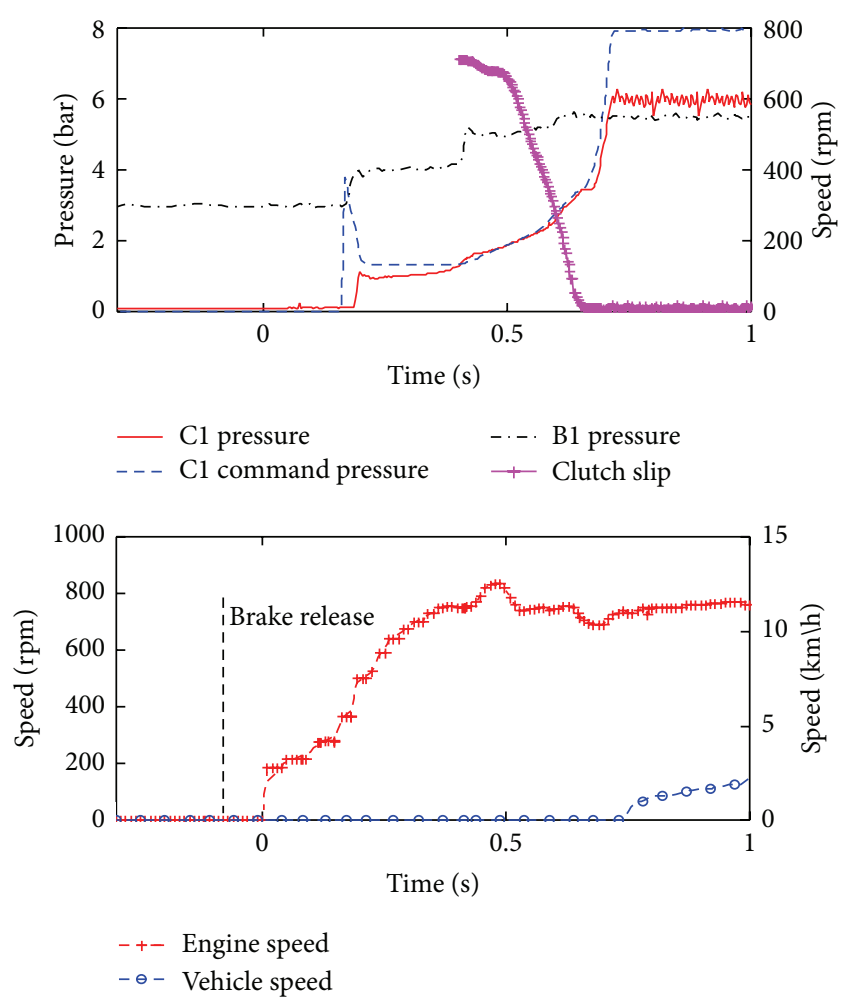

FIGURE 21: Vehicle test result of vehicle starting.

occurred because there was no torque delivering during this time. While driver released the brake pedal, the enhanced motor started operating; it took only $400 \mathrm{~ms}$ for the motor to drag engine to approximately $750 \mathrm{rpm}$; the rapid filling process of $\mathrm{C} 1$ was accomplished before the engine reached the idle speed; the clutch piston of $\mathrm{Cl}$ kept in the position of kisspoint for preparation of torque delivering. The vehicle started moving after the $\mathrm{Cl}$ entered into the speed phase and the delivered torque was enough for driving the vehicle. The clutch slip dropped stably to zero as the pressure of $\mathrm{Cl}$ increased; with the engine starting operation the pressure of $\mathrm{B} 1$ increases gradually to the pressure for clutch totally closed; the pressure of $\mathrm{C} 4$ was also controlled the same way as B1; the powertrain was totally closed at the end of speed phase; there was no delay in the torque delivery, all clutch actual pressures followed well with the command pressures. The time of the release of the brake until the vehicle driving off was less than $1 \mathrm{~s}$; the vehicle driving off quickly followed the action of the driver. Little shock was felt in the cockpit, and a smoother performance can be achieved by further development of the vehicle mounting and the coordinating calibration between AT and the engine.

\section{Conclusion}

(1) This study established a dynamics model of power loss and leakage for an 8AT.

(2) Based on the dynamics model, the flow requirement of the system was calculated and the control algorithm of EOP was developed. A heat transfer model 
between the ATF and shifting elements was created to optimize the control algorithm of the EOP.

(3) The two-pump system can achieve more fuel economy improvement than conventional AT hydraulic system.

(4) This study also developed a control strategy for the starting clutch. The rig and vehicle test results proved the feasibility of these control strategies. The control algorithm of the EOP can satisfy the start-stop function and requirement for the system cooling and lubrication. A quick and smooth vehicle starting performance was achieved by the control strategy of the starting clutch.

\section{Conflict of Interests}

The authors declare no conflict of interests regarding the publication of this paper.

\section{Acknowledgments}

The authors acknowledge the financial support provided by the National Science Foundation of China (51105017) and National Science and Technology Support Program of China (2011BAG09B00).

\section{References}

[1] A. Dhand and B. Cho, "Stop-Start Micro Hybrid: An Estimation of Automatic Engine Stop Duration in Real World Usage," SAE 2009-01-1336.

[2] H. Chen and C. Zuo, "Control strategy research of engine smart start/stop system for a micro car," SAE 2013-01-0585, 2013.

[3] H. Scherer and M. Bek, "ZF New 8-speed Automatic Transmission 8HP70-Basic Design and Hybridization," SAE 2009-010510 .

[4] H. Tomomatsu, Y. Tanaka, and K. Nakatani, "Automatic transmission control system developed for Toyota Mild Hybrid System (THS-M)," SAE 2002-01-1253, 2002.

[5] J. Dorfschmid, "7G-tronic plus for $1000 \mathrm{Nm}$," in Proceedings of the International VDI-Congress, Friedrichshafen, Germany, June 2012.

[6] R. Ahlawat, H. K. Fathy, B. Lee, J. L. Stein, and D. Jung, "Modelling and simulation of a dual-clutch transmission vehicle to analyse the effect of pump selection on fuel economy," Vehicle System Dynamics, vol. 48, no. 7, pp. 851-868, 2010.

[7] J. Y. Hwang, S. H. Jo, and T. H. Wi, "Development of two oil pumping system for automatic transmission," SAE Technical Paper 2014-01-1766, 2014.

[8] Y. Kim, M. Song, J. Kim, H. Lee, and H. Kim, "Power-based control of an electric oil pump for an automatic-transmissionbased hybrid electric vehicle," Proceedings of the Institution of Mechanical Engineers, Part D: Journal of Automobile Engineering, vol. 226, no. 8, pp. 1088-1099, 2012.

[9] X. Wang, R. McGee, and M. Kuang, "Vehicle System Control for Start-Stop Powertrains," SAE 2013-01-0347.

[10] L. Xi, W. Shuhan, L. Yanfang, and X. Xiangyang, "Application of clutch to clutch gear shift technology for a new automatic transmission," Journal of Central South University of Technology, vol. 19, pp. 2788-2796, 2012.

[11] Schaeffler Technical Pocket Guide, Schaeffler Technologies GmbH \& Co. KG, Herzogenaurach, Germany, 1st edition, 2014.

[12] S.-H. Wang, X.-Y. Xu, Y.-F. Liu, Z.-K. Dai, P. Tenberge, and W. $\mathrm{Qu}$, "Design and dynamic simulation of hydraulic system of a new automatic transmission," Journal of Central South University of Technology, vol. 16, no. 4, pp. 697-701, 2009.

[13] X. Li and X. Zhao, "Analysis of factor affecting lubricant viscosity," Lubricating Oil 1002-3119(2009)06-0059-06, 2009.

[14] Design Practices: Passenger Car Automatic Transmissions, SAE Book, Warrendale, Pa, USA, 4th edition, 2012.

[15] F. Andreas and G. Wohlleber, Thermischer Haushalt Nasslaufender Lamellenkupplungen, Fakultät für Maschinenwesen der Technischen Universität München, 2012. 


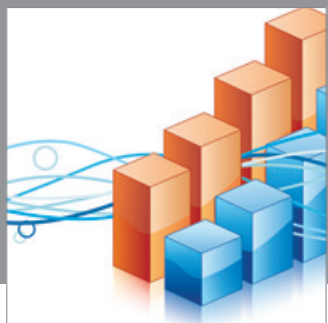

Advances in

Operations Research

mansans

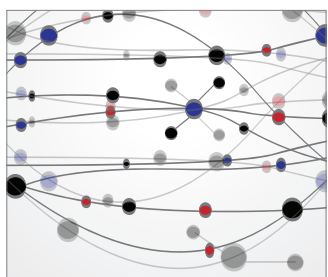

The Scientific World Journal
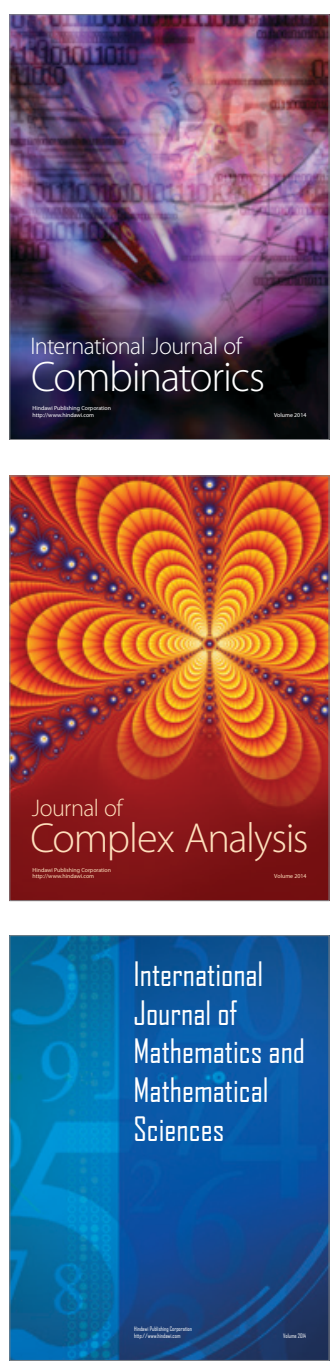
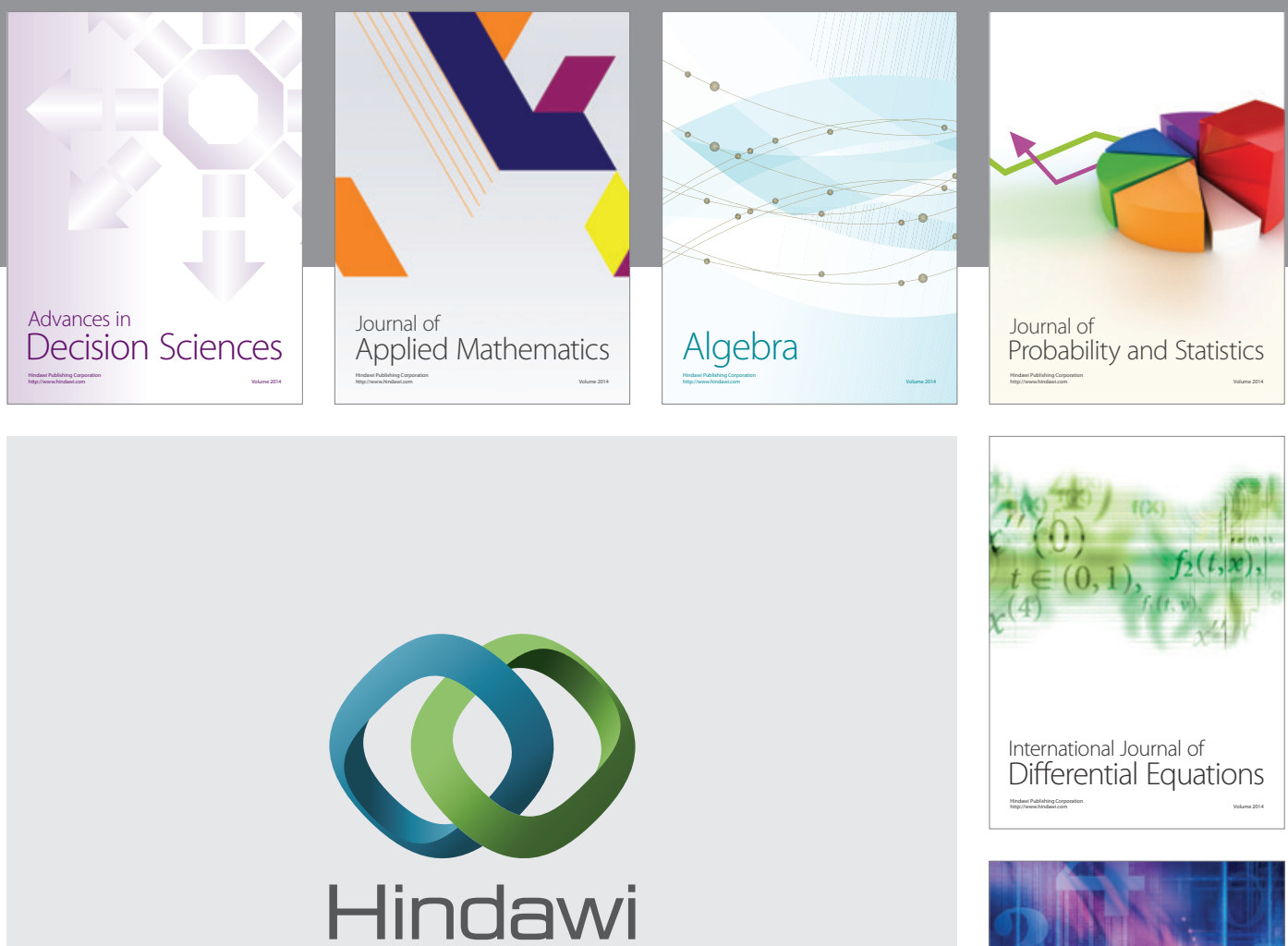

Submit your manuscripts at http://www.hindawi.com
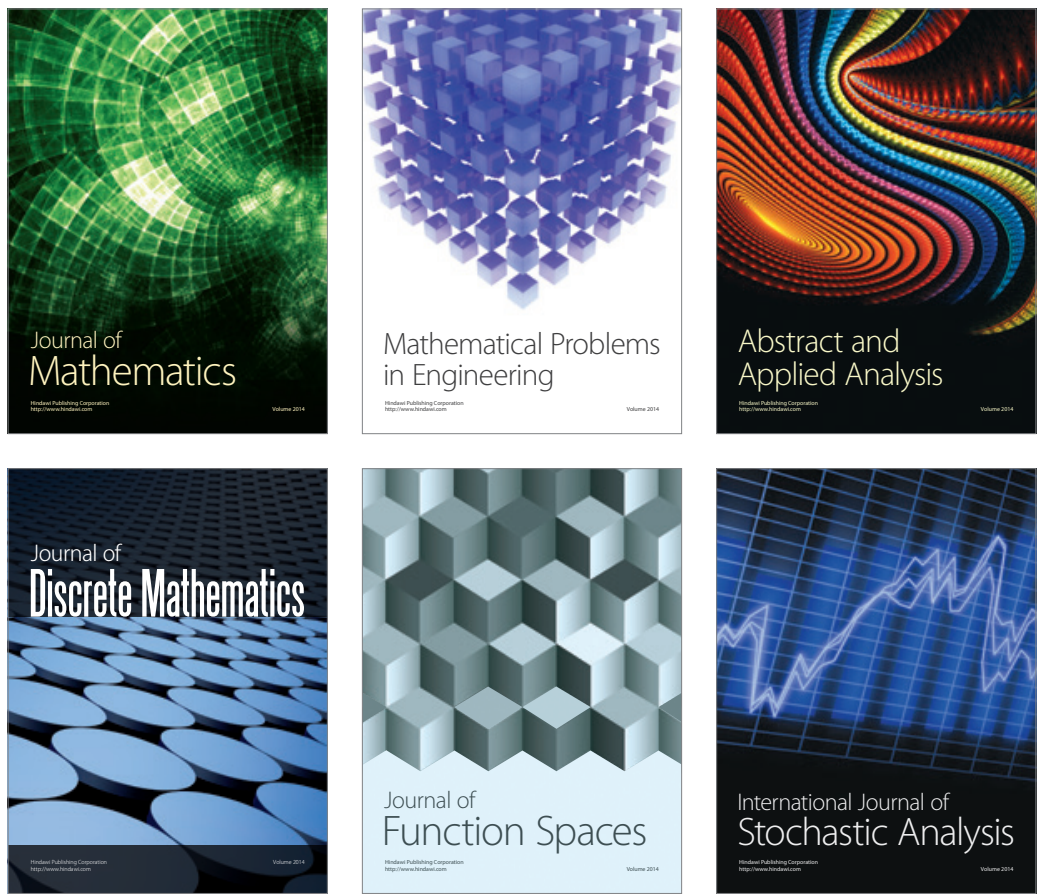

Journal of

Function Spaces

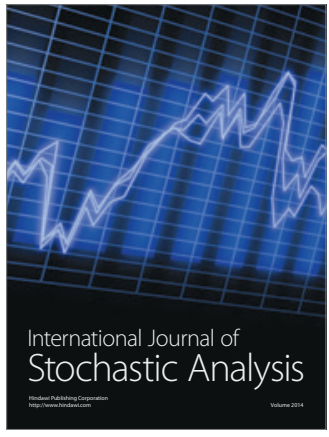

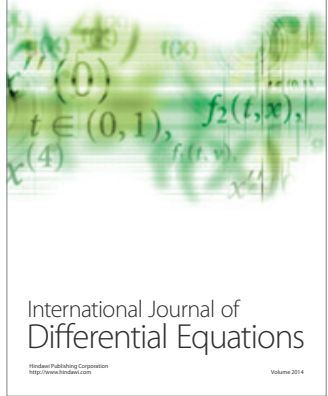
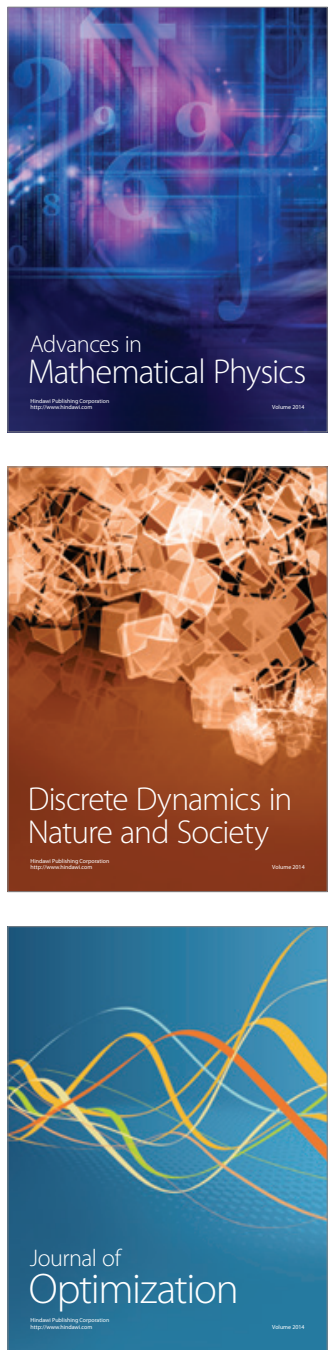